\title{
Key Regulatory Considerations for the Development of Biosimilar Pharmaceutical Products
}

\author{
Samrat Sisodia ${ }^{1}$ \\ ${ }^{I}$ (UGSM - Monarch University, Zug, Switzerland)
}

\begin{abstract}
Regulatory authorities are faced with different kinds of challenges when dealing with biosimilar products compared to other conventional generics. This is one of the reasons which made the FDA in the U.S. to delay authorizing biosimilars which have been in existence in Europe since 2005. Legal and scientific issues were sorted out in 2007 thus allowing the U.S. to approve Omnitrope and Valtropin. The BPCI Act was signed into law in 2009 and it was responsible for creating biological drug approval. Other important components of biosimilars are data exclusivity and patents whose aim are to preserve knowledge and innovation. They recognizes that an originator invest a lot of time and resources before producing a product. This document ends by discussing the challenges and opportunities of producing biosimilar products, and the issues to be considered before developing a biosimilar product.
\end{abstract}

Keywords -Biosimilars, Biologics, FDA, BPCI, Regulatory Strategies

\section{INTRODUCTION}

Senator Edward Kennedy first introduced and sponsored the Biologics Price Competition and Innovation Act of 2009 (BPCI Act) in 2007. Patient Protection and Affordable Care Act (PPAC Act) formally approved the BPCI Act, and President Obama signed it into law in 2010. Public Health Service Act (PHS Act) was amended to form BPCI Act to ensure that biological products have an abbreviated approval pathway which is demonstrated to be biosimilar to a biological product approved by FDA [1].

Conceptually, the BPCI Act has a close similarity with the Drug Price Competition and Patent Term Restoration Act of 1984. It is also commonly known as the "Hatch-Waxman Act", and it was responsible for creating biological drug approval [2]. The Federal Food, Drug, and Cosmetic Act (FFD\&C Act) was responsible for approving the creation of the biological drug. Chirino and Mire-Sluis [3] say that BPCI Act supports the longstanding policy by FDA which permits appropriate reliance on already established aspects of a drug [4]. This saves resources and avoids unnecessary duplication of animal and human testing.

Data exclusivity makes a crucial segment of Patient Protection and Affordable Care Act for biosimilars. It is the time period between approval by FDA and a biosimilar's abbreviated filing on the data of the original producer [5]. Data exclusivity aims at preserving innovation by recognizing the costly, lengthy and risky period which an innovator has to wait before being approved by FDA. Calo-Fernández and Martínez-Hurtado (2012) [6] say that for biosimilars to be approved, the legal requirements and high costs of manufacturing processes could run up to between $\$ 75$ and $\$ 250$ million per molecule. Patents give the innovator a grace period of recovering the high cost of research innovation. It is also a barrier to other market entrants who would be willing to produce inexpensive alternatives[7]. Experts predict that biosimilar products will cost $65 \%-85 \%$ of their originators. This paper will discuss the key regulatory provisions, scientific and quality challenges in developing a biosimilar and finally opportunities and challenges ahead of biopharmaceutical industry involved in developing a biosimilar drug.

\section{HISTORY AND CURRENT STATUS OF BIOSIMILAR PRODUCTS IN THE U.S}

Biosimilars, also referred to as follow-on biologics (FOPPs), can be defined as biologic medical products that are similar, but not identical, to clinically inactive components and reference products whose marketing approval has be submitted separately after the patents of the reference products expires [8]. Although biosimilars in the EU have been in existence since 2005, this process in the U.S. was delayed for many years after both Genentech and Pfizer filed a "Citizen's Petition" to prohibit FDA from approving biosimilars [9].Sandoz petitioned FDA to approve Omnitrope, which is a recombinant human growth hormone having an identical structure to Pfizer's Genotropin. Genotropin had already been approved under a new-drug application (NDA) in 1995. FDA failed to approve due to legal and scientific issues that were yet to be resolved. Four years of legal battle, Omnitrope and Valtropin were approved in 2007. 
After their approval, FDA permitted an abbreviated pathway with a minimum of six months clinical data from the phase III study. Omnitrope was approved because its protein structure is well characterized, mechanism of action is known, it lacks glycosylation, while its history of clinical use with efficacy and safety profile is long and well documented in the literature [10]. Currently, biosimilars have managed to lower costs but there are scientific issues which have made experts to doubt the safety and clinical utility of FOPPs. Therefore, post-marketing pharmacy- vigilance research studies will be required in the near future for all apart from the simplest FOPP. In 2007, FDA approved two biosimilar somatropinsOmnitrope (Sandoz) and Valtropin (LG Life Sciences, Biopartners) as a follow-in protein product[1].

\section{CHALLENGES AND OPPORTUNITIES}

Biopharmaceuticals have a complex manufacturing process that is of higher magnitude compared to small-molecule pharmaceuticals [11-12]. Conventional pharmaceuticals agents have a molecular weight of between 100 and $1000 \mathrm{Da}$ while the large biopharmaceuticals range from 18,000 to 145,000 Da. Changes or differences in the manufacturing process can have a major effect on purity, quality, and biological attributes of the final product [13]. The complex manufacturing process and the intrinsic physiochemical and structural heterogeneity has the ability of affecting their efficacy and safety. High costs of entry have locked out several potential entrants in the market.

There are several opportunities for biosimilars as biologic products increase across the world with a total value of over $\$ 150$ billion[14]as demonstrated in fig 1 .

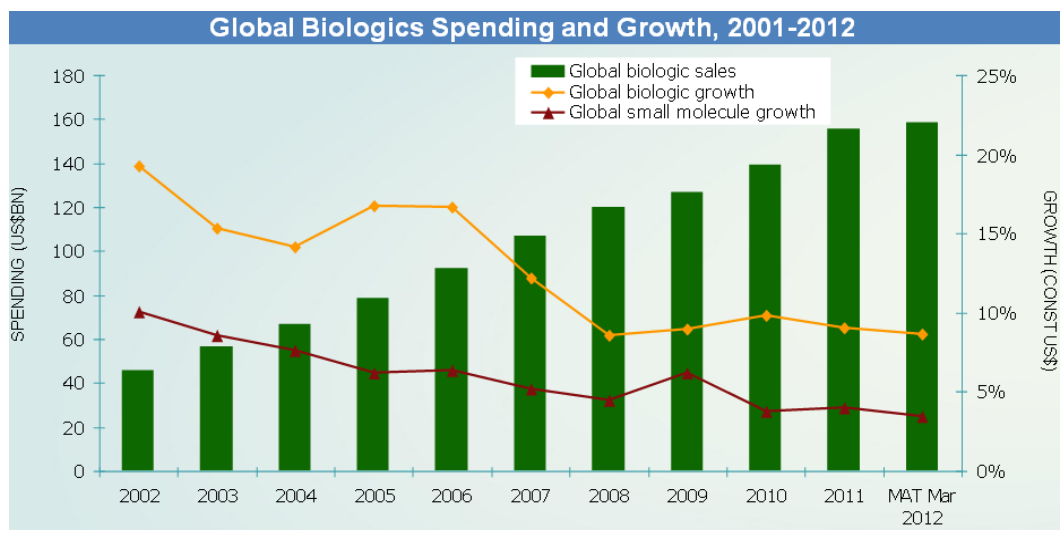

Figure 1Global biologics spending and growth, 2001-2012 (goldstandard.com, 2012)

Sponsors have also been coming around with more than 11 IND applications submitted and more than 30 meetings conducted by with FDA. Despite the fact that markets are highly regulated, and was only valued at $\$ 310$ in 2010 , markets have been increasing at a high rate [14].

Affordability of a biologic drug remains concerning to many lawmakers and insurance companies especially in the Unites States. The New York Times in 2010 published a finding which suggested than on an average a biologic drug cost 12 times more than a small molecule drug and some of the bestselling biologic drugs like Herceptin, Humira and Cerezyme may cost somewhere in between $\$ 37,000$ - 200,000/year to patients. In one estimate it is believed that top 6 selling biologic drugs alone consumed $43 \%$ of Medicare Part B aid in 2010.

Biosimilar drugs are expected to provide ease of excess and lower cost burden to avail necessary treatment for diseases requiring biologic drugs. Current sales projection and trends of prominent biologic drugs suggests that by 2016, 7 spots in top 10 drugs will be occupied by biology drugs. It makes all sense to develop biosimillars to these top selling drugs to avail market benefit.

Market analysis is an important consideration by small generic pharmaceutical companies. In different established markets like the U.S. and Europe, some companies have exclusive rights because their products have strictly enforced intellectual property laws [15]. Second, biosimilar drugs provide an opportunity of supplying patients with alternative drugs for quality treatment and lower prices. However, the company can only be successful if it achieves a predictable, transparent, and competitive market that is controlled by effective intellectual property and regulatory policies and systems. In the modern era of personalized medicine, businesses must analyze the issue of cost versus care [16]. Moreover, a company must have a clear understanding of the laws and regulations pertaining to biologic drugs in different countries. 


\section{KEY CONSIDERATIONS BEFORE INITIATING A BIOSIMILAR DRUG DEVELOPMENT}

Before initiating a biosimilar drug development, sponsors have to demonstrate comparability of a biosimilar with a reference product that is already licensed in a particular country. This reduces the possibility of making a similar biologic and giving it different brand names in different countries [17]. For instance, rituximab is sold as Rituxan in the U.S., while in other countries, it is called MabThera. Another crucial consideration is the place where the reference product was manufactured. This assists in analyzing regulations which govern export and import of pharmaceuticals and its impact on supplies of clinical trials. Also to be analyzed is the exclusivity and patent considerations [18].

The strictest regulation is by FDA and EMA which demands for a comprehensive functional and structural analytic and comparative data to show any form of comparability before animal testing and clinical PK/PD can be initiated [19]. Biochemical analytical data as well as the results of in vitro pharmacological tests are utilized to establish if in vivo studies are required and the way they should be designed. PK data acts as the basis of the clinical program and trials at different dose levels. Some of the operational requirements include recruitment of physicians, clinical supplies considerations, reimbursement, and research incentives where patients are compensated for participating in the trials [20].

\section{CONCLUSION}

In conclusion, Biosimilar products are considered as complex molecules which imply that they must be treated differently from other conventional drugs. This is the main reason why it took considerable amount of time before the FDA could authorize biosimilar products in the U.S. Biosimilars have to pass through comprehensive tests during the production process so that they can be compared to a particular reference product. This reduces the chance of a single product being marketed under different brand names in different countries. The manufacturing process is considered as the most challenging aspect of biosimilar products due to their huge molecular weight and ability to change physical attributes. Before starting the development of biosimilar products, sponsors need to demonstrate comparability of biosimilar drug with a reference product. A firm also needs to analyze the market conditions and government policies before setting up an organization.

\section{REFERENCES}

[1] Ahmed I, Kaspar B, Sharma U. (2012). Biosimilars: impact of biologic product life cycle and European experience on the regulatory trajectory in the United States. Clinical Therapeutics. Vol.34 (2): pp. 400-19. http://www.ncbi.nlm.nih.gov/pubmed/22244050

[2] Humi, R., A. (2012). Pharmaceutical Competitive Intelligence for the Regulatory Affairs Professional. New York: Springer

[3] Chirino, A., J., \& Mire-Sluis, A. (2004). Characterizing biological products and assessing comparability following manufacturing changes. National Biotechnology. Vol.22: pp.1383-1391.

[4] Schellekens, H. (2008b). The first biosimilar epoetin: but how similar is it? Clinical Journal of American Social Nephrology . Vol.3: pp.174-178.

[5] Declerck, P., J. (2013). "Biosimilar monoclonal antibodies: a science-based regulatory challenge". Expert Opinion on Biological Therapy. 13 (2): 153-6

[6] Calo-Fernández, B, Martínez-Hurtado, J. (2012). "Biosimilars: Company Strategies to Capture Value from the Biologics Market". Pharmaceuticals 5 (12): 1393-1408.

[7] Prugnaud, J \&Trouvin, J. (2012). Biosimilars: A New Generation of Biologics. New York: Springer.

[8] Crommelin, D., J., Bermejo, T, \&Bissig, M, et al. (2005). Pharmaceutical evaluation of biosimilars: important differences from generic low-molecular weight pharm. European Journal of Hospital Pharmacy Science and Practice vol.1: pp.11-17.

[9] Dudzinski, D., M., \&Kesselheim, A., S. (2008). Scientific and legal viability of follow-on protein drugs. The New England Journal of Medicine 2008, 358 (8):pp. 843-849.

[10] Ranke, M., B. (2007). New preparations comprising recombinant human growth hormone: deliberations on the issue of biosimilars. Hormone Research. Vol. 69(1): pp.22-28.

[11] Schellekens, H. (2005). Factors influencing the immunogenicity of therapeutic proteins. Nephrology Dialysis Transplantation. Vol.20: pp. vi3-vi9.

[12] Wiecek, A, \& Mikhail, A. (2006). European regulatory guidelines for biosimilars. Nephrology Dialysis Transplantation. Vol. 6; i. 21(Suppl 5): pp. v17-v20.

[13] Roger, S., D. (2006). Biosimilars: how similar or dissimilar are they? Nephrology (Carlton). Vol.11: pp.341-346.

[14] goldstandard.com, (2012). Biosimilars - U.S. and International Update. Retrieved September 13, 2013, from http://www.goldstandard.com/wp-content/uploads/Biosimilars\%E2\%80\%93US-and-International-Update.pdf

[15] Rotenstein, L., S., Ran, N, Shivers, J., P., Yarchoan, M \& Close, K., L. (2013). Opportunities and Challenges for Biosimilars: What's on the Horizon in the Global Insulin Market? Drug and Therapeutics Bulletin July 1, 51:78-81

[16] Kessler, M, Goldsmith, D, \&Schellekens, H. (2006). Immunogenicity of biopharmaceuticals. Nephrology Dialysis Transplantation. Vol .21(Suppl 5): pp.v9-v12.

[17] healthtrustpg.com (2013). Developing Biosimilars in Emerging Markets: Regulatory and Clinical Considerations. Retrieved September 13, 2013, from http://www.healthtrustpg.com/biosimilars/pdf/ppd.pdf

[18] fda.gov (2012). Guidance for Industry Scientific Considerations in Demonstrating Biosimilarity to a Reference Product. Retrieved September 13, 2013, from http://www.fda.gov/downloads/Drugs/GuidanceComplianceRegulatoryInformation/Guidances/UCM291128.pdf

[19] Locatelli, F., \& Roger, S. (2006). Comparative testing and pharmacovigilance of biosimilars. Nephrology Dialysis Transplantation. Vol. 21(Suppl 5): pp.v13-v16.

[20] Pitts, P., J., \& Stark, R. (2012). Biosimilars: The Precarious Struggle between Cost-driven Health Care Policy and Patient-centered Care. Retrieved September 13, 2013, from http://www.washingtonpolicy.org/publications/brief/biosimilars-precarious-strugglebetween-cost-driven-health-care-policy-and-patient 